\title{
Performance Analysis of Constant-Pressure Pumped Hydro Combined with Compressed Air Energy Storage System Considering Off-Design Model of Compressor
}

\author{
Xin He, Huanran Wang*, Feiyue Tao, Gangqiang Ge \\ School of Energy and Power Engineering, Xi'an Jiaotong University, Xi'an, China \\ Email: hx09130032@stu.xjtu.edu.cn, ^huanran@xjtu.edu.cn
}

How to cite this paper: He, X., Wang, H.R., Tao, F.Y. and Ge, G.Q. (2021) Performance Analysis of Constant-Pressure Pumped Hydro Combined with Compressed Air Energy Storage System Considering Off-Design Model of Compressor. Energy and Power Engineering, 13, 11-18.

https://doi.org/10.4236/epe.2020.134B002

Received: January 16, 2021

Accepted: April 5, 2021

Published: April 8, 2021

\begin{abstract}
With the wide application of renewable energy, energy storage technology has become a research hotspot. In order to overcome the shortcomings of energy loss caused by compression heating in compressed air energy storage technology, a novel constant-pressure pumped hydro combined with compressed air energy storage system was proposed. To deepen the understanding of the system and make the analysis closer to reality, this paper adopted an off-design model of the compressor to calculate and analyze the effect of key parameters on system thermodynamics performance. In addition, the results of this paper were compared with previous research results, and it was found that the current efficiency considering the off-design model of compressor was generally $2 \%-5 \%$ higher than the previous efficiency. With increased preset pressure or with decreased terminal pressure, both the previous efficiency and current efficiency of the system increased. The exergy destruction coefficient of the throttle valve reached $4 \%$. System efficiency was more sensitive to changes in water pump efficiency and hydroturbine efficiency.
\end{abstract}

\section{Keywords}

Energy Storage, Compressed Air Energy Storage, Off-Design Model

\section{Introduction}

With the rapid development of the new energy industry, it is becoming more and more urgent to solve the inherent randomness and instability of new energy sources. Researchers believe that compressed air energy storage (CAES) technology is one of the physical technologies to solve the intermittent new energy 
grid-connected and the power grid peaking [1] [2]. In recent years, CAES has become a research hotspot at home and abroad. Based on the new compression principle, Wang et al. proposed a novel pumped hydro combined with CAES system (PHCA) [3]. Yao et al. improved the new system and performed a thermodynamic analysis of the system [4]. Zhang et al. did an off-design condition analysis on the throttle valve in CAES system [5]. Great progress has been made in this field, but the above studies were based on the work of the compressor in the rated working conditions, and there were big differences from the actual operation. The off-design model of the machine is more in line with the actual situation. This paper calculated and analyzed the performance of the constant-pressure PHCA system by applying the off-design condition calculation model of compressor, and compared the calculation results with the previous research results to provide a theoretical reference for the actual operation of the constant-pressure PHCA system.

\section{System Description}

A schematic diagram of a constant-pressure PHCA is depicted in Figure 1. The operation of the system can be divided into pre-compression process, charging and dis-charging periods.

1) Pre-compression process: before the charging process, valves 1,2 and compressor $\mathrm{C} 1$ were opened. When the air pressure in the storage vessel and high-pressure vessel to a set value, valves 1 and 2 were closed and compressor C1 was stopped.

2) Charging process: by opening the valves 3 and 4, water was injected from the water tank into the storage vessel through the water pump. At the same time, valve 5 was opened, and the compressor $\mathrm{C} 2$ was started to pressurize the air from the storage vessel into the high-pressure vessel. In this process, by controlling the flow of the water pump and compressor $\mathrm{C} 2$, the pressure in the storage vessel remained constant. As the injection volume reached the set value, the water pump and compressor $\mathrm{C} 2$ were stopped while valves were closed.

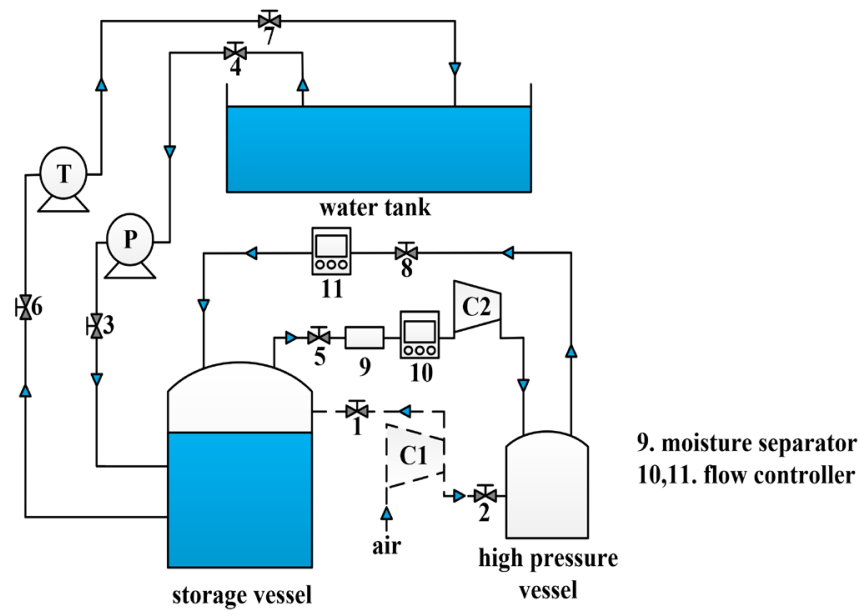

Figure 1. Schematic of the constant-pressure PHCA [4]. 
3) Dis-charging process: valves 6 and 7 were opened, and the water in the storage vessel pushed the hydroturbine to work. Then it flowed into the water tank. Meanwhile, the valve 8 was opened, which allowed the air in the high-pressure vessel flows into the storage vessel through the throttle valve. In this process, by controlling the flow of the hydroturbine and throttle valve, the pressure in the storage vessel remained constant.

\section{Mathematical Model}

In order to simplify the analysis of the constant-pressure PHCA system, the following assumptions were made:

1) Air is an ideal gas, and its dissolution in water is ignored;

2) Water is an incompressible fluid;

3) High-pressure vessels and storage vessels are adiabatic vessels;

4) Ignore pressure changes due to fluid level changes;

5) Ignore energy loss due to resistance in the pipeline.

Yao had built the basic thermodynamic model and analyzed the thermodynamic performance of the constant-pressure PHCA system while the compressor C2 is working in design conditions [4]. To be more realistic, this paper applied the off-design condition calculation model of the compressor with other models and parameters were unchanged and focused on the thermodynamic performance of the constant-pressure PHCA system under variable working conditions. Table 1 shows the values of the main parameters used in the model.

\subsection{Compressors}

During the charging process, the air pressure in the storage vessel remained

Table 1. Main parameters and their values of constant-pressure PHCA system [4].

\begin{tabular}{ccc}
\hline Parameters & Unit & Value \\
\hline Ambient temperature & $\mathrm{K}$ & 298 \\
Ambient pressure & $\mathrm{Pa}$ & 101,330 \\
Volume of storage vessel & $\mathrm{m}^{3}$ & 40 \\
Adiabatic index & - & 1.4 \\
Gas constant & $\mathrm{J} \cdot \mathrm{kg}^{-1} \cdot \mathrm{K}^{-1}$ & 287 \\
Constant pressure specific heat of air & $\mathrm{J} \cdot \mathrm{kg}^{-1} \cdot \mathrm{K}^{-1}$ & 1004.5 \\
Specific heat of water & $\mathrm{J} \cdot \mathrm{kg}^{-1} \cdot \mathrm{K}^{-1}$ & 4200 \\
Density of water & ${\mathrm{kg} \cdot \mathrm{m}^{-3}}^{-1000}$ \\
Efficiency of water pump & $\%$ & 88 \\
Efficiency of hydroturbine & $\%$ & 90 \\
Design efficiency of compressor & $\%$ & 88 \\
Preset pressure & $\mathrm{Pa}$ & $3,000,000$ \\
Terminal pressure in the high pressure vessel & $\mathrm{Pa}$ & $4,000,000$ \\
\hline
\end{tabular}


constant by adjusting the flow of the water pump and compressor C2. However, the air pressure in the high-pressure vessel was constantly increasing due to the inflow of air. Therefore, the pressure ratio of compressor C2 was constantly changing, and it worked under variable working conditions. We applied off-design calculations through compressors characteristic maps that defined relative pressure ratio $\varepsilon_{c}$ and relative efficiency $\eta_{c}$ [6]. The definitions for pressure ratio and relative efficiency of Equation (1) and Equation (2) are the following ones:

$$
\begin{gathered}
\varepsilon_{c}=c_{1}\left(\dot{G}_{c}\right)^{2}+c_{2} \dot{G}_{c}+c_{3} \\
\eta_{c}=\left[1-c_{4}\left(1-\dot{n}_{c}\right)^{2}\right]\left(\dot{n}_{c} / \dot{G}_{c}\right)\left(2-\left(\dot{n}_{c} / \dot{G}_{c}\right)\right)
\end{gathered}
$$

where $\dot{G}_{c}$ and $\dot{n}_{c}$ are the reduced flow rate and the reduced speed, respectively.

$$
\begin{gathered}
\dot{G}_{c}=\left(\dot{m}_{c} \sqrt{T_{c, i n}} / P_{c, i n}\right) /\left(\dot{m}_{c} \sqrt{T_{c, i n}} / P_{c, \text { in }}\right)_{0} \\
\dot{n}_{c}=\left(n_{c} / \sqrt{T_{c, i n}}\right) /\left(n_{c} / \sqrt{T_{c, i n}}\right)_{0} \\
c_{1}=\dot{n}_{c} /\left[p\left(1-\frac{m}{\dot{n}_{c}}\right)+\dot{n}_{c}\left(\dot{n}_{c}-m\right)^{2}\right] \\
c_{2}=\left(p-2 m \dot{n}_{c}^{2}\right) /\left[p\left(1-\frac{m}{\dot{n}_{c}}\right)+\dot{n}_{c}\left(\dot{n}_{c}-m\right)^{2}\right] \\
c_{3}=-\left(p m \dot{n}_{c}-m^{2} \dot{n}_{c}^{3}\right) /\left[p\left(1-\frac{m}{\dot{n}_{c}}\right)+\dot{n}_{c}\left(\dot{n}_{c}-m\right)^{2}\right] \\
c_{4}=0.3
\end{gathered}
$$

The definitions for pressure ratio and relative efficiency of Equation (1) and Equation (2) are the following ones:

Among them, $c_{1}, c_{2}, c_{3}, c_{4}, \dot{G}_{c}$ and $\dot{n}_{c}$ can be calculated using the following Equation (3) and Equation (4).

Subscript 0 in Equation (3) and Equation (4) denotes design conditions while $p=1.8$ and $m=1.8$.

\subsection{Storage Vessel}

Considering that the temperature of the gas flowing from the throttle into the storage vessel was constantly changing, the average temperature in the storage vessel would also change. From the state equation of ideal gas, the gas pressure would also change. We calculated the temperature in the storage vessel according to Equation (5).

$$
\delta Q=\mathrm{d} E_{C V}+h_{\text {out }} \delta m_{\text {out }}-h_{\text {in }} \delta m_{\text {in }}
$$

where $\delta Q$ is the heat transfer between the air in the storage vessel and the environment, $\mathrm{d} E_{C V}$ is the inner energy change of air in the storage vessel, $\delta m_{\text {out }}$ and $\delta m_{\text {in }}$ are the mass of air flow out and flow in storage vessel respectively.

Because the storage vessel is adiabatic, so $\delta Q=0$. And calculated the pres- 
sure in the storage using the following Equation (6).

$$
P=m_{s} R_{g} T / V_{s}
$$

\section{Results and Discussion}

System efficiency varied with the main thermodynamic parameters in the system. The analyses were performed for the constant-pressure PHCA system. Figure 2 shows that both the previous efficiency and current efficiency of the system increased with increased preset pressure or decreased with the increased terminal pressure. Interestingly, the current efficiency is always higher than the previous efficiency during preset pressure and terminal pressure changes. It means that the smaller the pressure difference between storage vessel and high pressure vessel, the higher the system efficiency of the constant-pressure PHCA system. What's more, the system efficiency considering the off-design model of

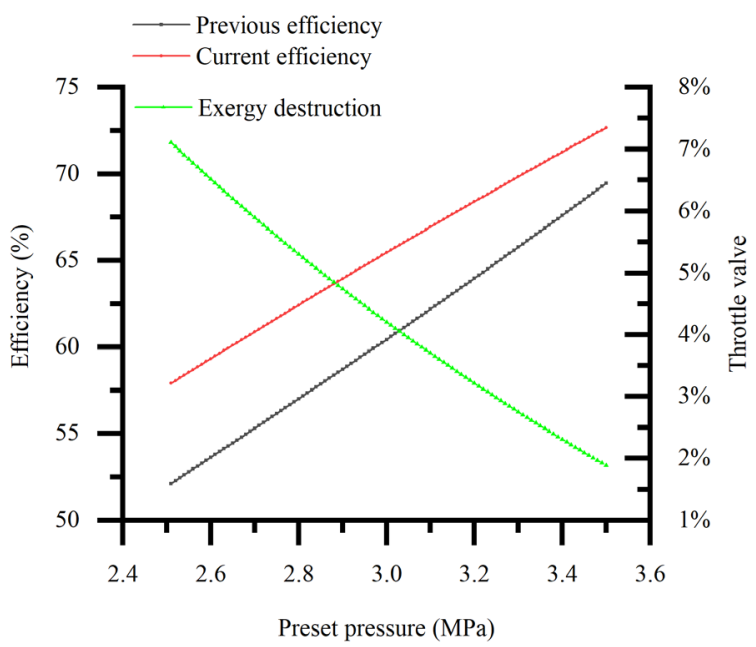

(a)

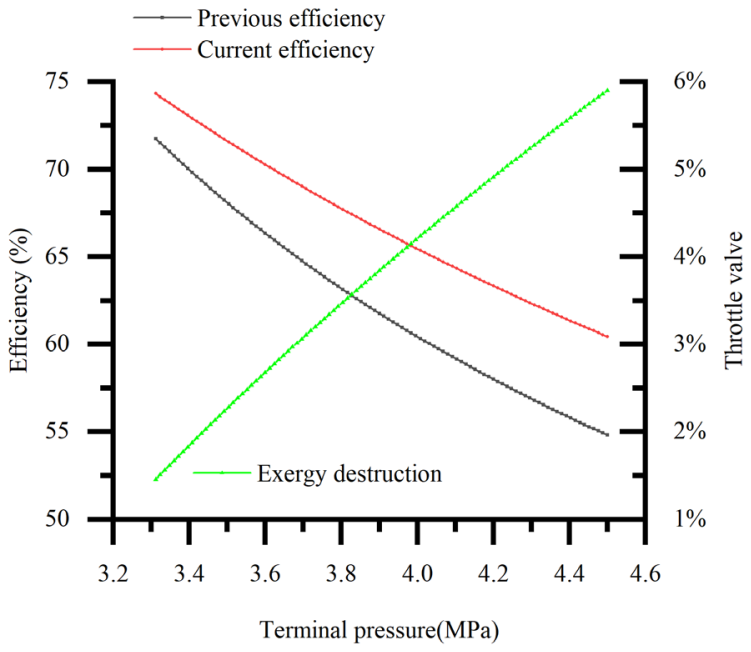

(b)

Figure 2. The effect of pressure on system efficiency and exergy destruction. (a) the variation of preset pressure; and (b) the variation of terminal pressure. 
the compressor was higher than the system efficiency when the compressor always working in design operating conditions. Through analysis, we found that although the efficiency of the compressor was reduced under off-design conditions, the working mode of changing the pressure ratio makes the pressure ratio of the compressor not need to be maintained at the maximum pressure ratio all the time. This mode effectively saved the power consumption of the compressor.

The effect of preset pressure and terminal pressure on the exergy destruction of the throttle valve was also illustrated in Figure 2. The exergy destruction coefficient of the throttle valve decreased while the preset pressure increased and the exergy destruction coefficient of the throttle valve increased while the terminal pressure increased. Obviously, the larger the pressure difference before and after the throttle valve, the larger the exergy destruction coefficient of the throttle valve. In this system, the exergy destruction in the throttle was indispensable.

Figure 3 shows that both the previous efficiency and current efficiency of the system changes with mechanical efficiency: the system efficiency considering the off-design model of the compressor was also higher than the system efficiency when the compressor always working in design operating conditions and the system efficiency increased with increased mechanical efficiency. From Figure 3

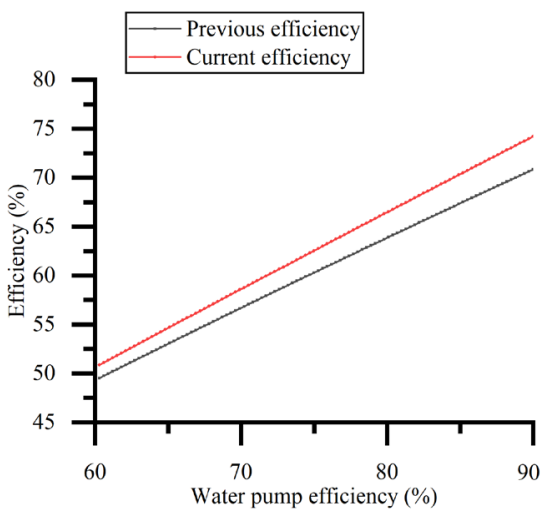

(a)

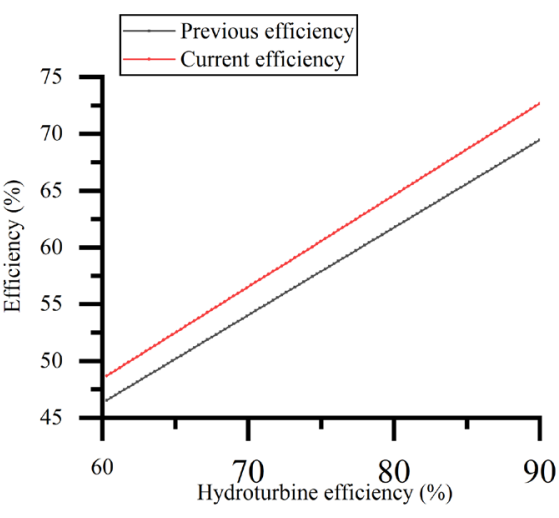

(b)

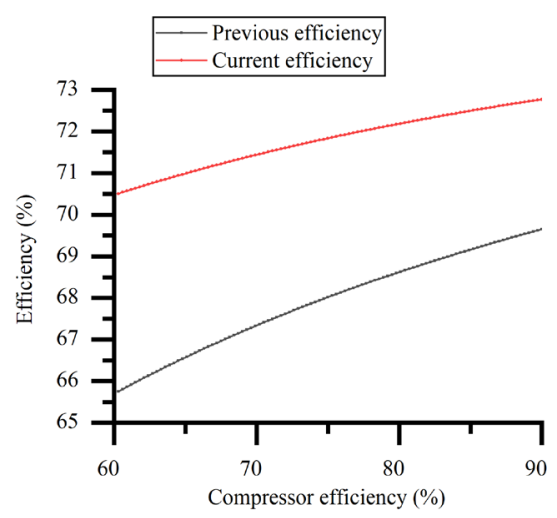

(c)

Figure 3. The effect of component's efficiency on round-trip efficiency. (a) the variation of water pump efficiency; (b) the variation of hydroturbine efficiency; and (c) the variation of compressor efficiency. 
we could also see that the system efficiency was more sensitive to the changes in water pump efficiency and hydroturbine efficiency. Therefore, in order to improve system efficiency, we should pay more attention to improving the performance of water pumps and hydroturbines.

\section{Conclusions}

In this paper, the off-design condition calculation model of the compressor was applied and the system efficiency varying with main thermodynamic parameters was analyzed. The analysis of the constant-pressure PHCA system suggested that the system efficiency considering the off-design model of the compressor was generally $2 \%$ - $5 \%$ higher than the system efficiency when the compressor always works in design operating conditions. What's more, with increased preset pressure or with decreased terminal pressure, both the previous efficiency and current efficiency of the system increased. The system efficiency increased with increased mechanical efficiency, especially water pump efficiency and hydroturbine efficiency. In this system, the exergy destruction coefficient of the throttle valve reached $4 \%$.

In short, this paper analyzed the constant-pressure PHCA system by applying the off-design model of the compressor to make the analysis result more in line with the actual situation. This paper has guiding significance for the practical application of the constant-pressure PHCA system. As research progresses, however, and the depth of knowledge increases, it is important for researchers to analyze the thermodynamic performance of the system considering off-design models of all components of the system.

\section{Conflicts of Interest}

The authors declare no conflicts of interest regarding the publication of this paper.

\section{References}

[1] Bove, R., Bucher, M. and Ferretti, F. (2012) Integrating Large Shares of Wind Energy in Macro-Economical Cost-Effective Way. Energy, 43, 438-447. https://doi.org/10.1016/j.energy.2012.03.061

[2] Yuan, X., Cheng, S. and Wen, J. (2013) Analysis of Application Prospects of Energy Storage Technology in Solving Large-Scale Wind Power Grid Connection Problems. Automation of Electric Power Systems, 37, 14-18.

[3] Wang, H., Wang, L., Wang, X. and Yao, E. (2013) A Novel Pumped Hydro Combined with Compressed Air Energy Storage System. Energies, 6, 1554-1567. https://doi.org/10.3390/en6031554

[4] Yao, E., Wang, H., Liu, L. and Xi, G. (2015) A Novel Constant-Pressure Pumped Hydro Combined with Compressed Air Energy Storage System. Energies, 8, 154-171. https://doi.org/10.3390/en8010154

[5] Zhang, S., Wang, H., Li, R., et al. (2019) Thermodynamic Analysis of Cavern and Throttle Valve in Large-Scale Compressed Air Energy Storage System. Energy Conversion and Management, 183, 721-731. 
https://doi.org/10.1016/j.enconman.2018.11.055

[6] Sciacovelli, A., Li, Y., Chen, H., et al. (2017) Dynamic Simulation of Adiabatic Compressed Air Energy Storage (A-CAES) plant with Integrated Thermal Storage-Link between Components Performance and Plant Performance. Applied Ener$g y$, 185, 16-28. https://doi.org/10.1016/j.apenergy.2016.10.058 